\title{
Activation of porous Si blue emission due to preanodization ion implantation
}

\author{
A.G. Rozhin, N.I. Klyui, V.G. Litovchenko, V.P. Melnik, B.N. Romanyuk, Yu.P. Piryatinskii* \\ Institute of Semiconductor Physics, 41 prospect Nauki, 03028, Kiev, Ukraine \\ E-mail:rozhin@isp.kiev.ua \\ *Institute of Physics, 46 prospect Nauki, 03022, Kiev, Ukraine
}

\begin{abstract}
Implantation of $\mathrm{B}^{+}, \mathrm{N}^{+}$, and $\mathrm{B}^{+}+\mathrm{N}^{+}$ions into initial silicon wafers was carried out before anodization process. The results of photoluminescent (PL) study of porous Si samples prepared on $\mathrm{B}^{+}$or $\mathrm{N}^{+}$implanted wafers show a decrease in the photoluminescence intensity when compared with the initial porous $\mathrm{Si}$. In contrast to this, the $\mathrm{B}^{+}+\mathrm{N}^{+}$double doped samples show the increasing of the photoluminescence intensity. This effect can be explained by donor-acceptor pairs formation, and, as a result, the new recombination-active radiative channel creation. Rapid thermal annealing (RTA) treatment leads to significant decrease of PL intensity in the longwave spectral range for initial sample and samples prepared on implanted substrates. Furthermore, RTA treatments leads to the activation of the porous Si high-energy $\mathrm{PL}$ formed on the $\mathrm{B}^{+}$implanted wafers.
\end{abstract}

Keywords: photoluminescence, porous $\mathrm{Si}$, implantation.

Paper received 30.01.01; revised manuscript received 05.02.01; accepted for publication 16.02.01.

\section{Introduction}

The discovery of efficient luminescence from porous silicon [1] has promised to extend industrial applications of silicon based technology. Ten years of the material study have set some questions about the nature of the emission, but the real applications of porous silicon still have prospects as at the beginning of the investigations. This disappointing fact reflects the following reasons. First of all, the wide variations of optical properties in connection with porous silicon preparation techniques that have been realized by different scientific groups. It has caused ambiguity in the materials physical properties interpretations. On the other hand, the most important fact that prevents applications of porous silicon is instability of optical parameters. In this connection, the most interesting works are directed toward the improving porous silicon degradation properties and studying luminescence mechanisms of the material.

The promising way to overcome above mentioned problems is implantation of different ions into the porous $\mathrm{Si}$ or initial Si wafers. The implantation can significantly decrease the resistance of a porous Si layer by introducing the doping impurities [2], which is necessary in order to obtain effective electroluminescent structures based on porous Si layers. The traditional attempts for reaching this goal by using the high temperature impurity activation diffusion processes leads to irreversibly decrease the photoluminescent (PL) intensity and change of PL spectrum position [2]. The main advantage of ion implantation is the possibility of the controllable impurity introduction under the normal temperature conditions. A disadvantage is the production of implantation defects. For reduction of their amount the post- implantation annealing is necessary. The authors [2] demonstrated that the intensity of PL is decreased after implantation of $\mathrm{Si}$, $\mathrm{B}, \mathrm{P}$ ions and following annealing. The implantation of inert gas ions into porous Si layer decreases the emission intensity $[2,3]$. These experiments demonstrated the heightened radiation stability of porous Si layers when compare with single-crystalline Si wafers [4].

The perspective way to manage spectral characteristics of porous $\mathrm{Si}$ is the ion modification of the initial $\mathrm{Si}$ wafers (before electrochemical etching). The blue emission was observed from porous $\mathrm{Si}$ samples formed on $\mathrm{C}^{+}$ implanted wafers and explained by formation of $\beta$-SiC precipitates that cause the decrease of silicon wire length [5] and even by the emission from porous Si [6]. Pavesi et al. [7] proposed the controllable method for change of the porous Si porosity by using the implantation of $\mathrm{Si}$ 


\section{A.G. Rozhin et al.: Activation of porous Si blue emission due to preanodization ...}

ions into initial wafers. In this context, the aim of our work was to study the effect of preanodizing implantation of $\mathrm{B}^{+}$and $\mathrm{N}^{+}$ions on the PL properties of porous $\mathrm{Si}$.

\section{Experimental}

Porous Si layers were fabricated by anodizing of $10 \Omega \mathrm{cm}$ p-type $\mathrm{Si}(100)$ substrates with aluminium rear contact. The electrolyte was $49 \% \mathrm{HF}: \mathrm{C}_{2} \mathrm{H}_{5} \mathrm{OH}=1: 1$, the current density was for series: (1) $-30 \mathrm{~mA} / \mathrm{cm}^{2}$ with a time of $3 \mathrm{~min}$, and (2) $-50 \mathrm{~mA} / \mathrm{cm}^{2}$ with a time of $5 \mathrm{~min}$.

The hot implantation $\left(T_{\text {substrate }}=700 \mathrm{~K}\right)$ of $\mathrm{B}^{+}, \mathrm{N}^{+}$, and $\mathrm{B}^{+}+\mathrm{N}^{+}$ions into initial silicon wafers was carried out prior to anodization process. The regime was: $\mathrm{E}=175$ $\mathrm{keV}$, implantation dose was $2 \times 10^{15} \mathrm{~cm}^{-2}$ for $\mathrm{B}^{+}$only, $\mathrm{N}^{+}$ ions and total dose was $4 \times 10^{15} \mathrm{~cm}^{-2}$ for combined $\mathrm{B}^{+}+\mathrm{N}^{+}$ implantation. The ions were implanted into the substrate with a normal beam incidence.

The samples of porous Si prepared on initial and ion modified Si wafers were subjected to pulse rapid thermal annealing (RTA) in an argon environment. The treatment temperature was 800 or $1100 \mathrm{~K}$, and time of annealing was 30 seconds.

The photoluminescence (PL) spectra were excited using a nitrogen laser $\left(\lambda_{\mathrm{ex}}=337.1 \mathrm{~nm}, \tau=10 \mathrm{~ns}, P=5 \mathrm{~kW}\right)$. For detecting time-resolved photoluminescence, the stroboscopic registration system was used. This gives the possibility to study kinetics and photoluminescence spectra with the time delay related to the maximum of the laser impulse.

\section{Results and discussion}

The results of photoluminescent study of first series porous $\mathrm{Si}$ prepared on modificated wafers are shown in Fig. 1. Initial porous-Si (prepared on Si wafer without ion modification) has pohotoluminescent band characterized by $680 \mathrm{~nm}$ peak position in integral spectra (curve 1). The emission in this spectral region is usually connected with appearances of quantum confinement effects [8]. The $\mathrm{B}^{+}$(curve 2 ) or $\mathrm{N}^{+}$(curve 3 ) only ion implantation leads to a substantial decrease in the photoluminescence intensity when compared with the initial porous $\mathrm{Si}$ intensity (curve 1). This effect, as well for glow discharge fabricated a:Si:H films, can be caused by internal electric fields, which created by charged donors and acceptors [9]. The electric fields suppress the recombination active transitions and, as a result quench the photoluminescence. Besides, the defect levels produced by ion implantation can create additional channels of nonradiative recombination and decrease the PL intensity. The fluctuation of PL band maximum that is observed on implanted samples is also supporting these assumptions. In contrast to this, the samples subjected to $\mathrm{B}^{+}+\mathrm{N}^{+}$double doping show (curve 4) the increase of the photoluminescence intensity. Compensation effects like doping into amorphous Si can explain this fact. The compensation reduces the level of nonradiative recombination such as

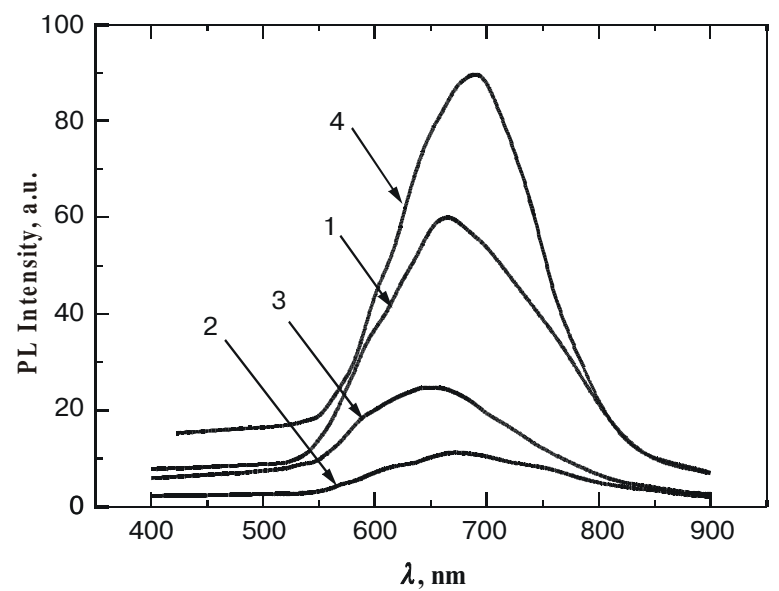

Fig. 1. Integrated PL spectra of the first porous silicon series formed on (1) initial (unimplanted) $\mathrm{Si}$ wafers and on the $\mathrm{Si}$ implanted with (2) $\mathrm{B}^{+}$ions, (3) $\mathrm{N}^{+}$ions, (4) $\mathrm{B}^{+}+\mathrm{N}^{+}$combined implantation

the surface dangling bonds and, as a result, creates additional levels similar to impurity complexes that is active in recombination.

Fig. 2 gives PL spectra of characteristic for samples the second series. According to review data [10], this variation of the preparation regimes leads to increasing porosity and thickness of the porous Si layers. As shown in [11], the porosity increasing of the porous Si samples manifested itself in increasing integrated intensity of PL band. The same spectral behavior was observed for all samples for the second series comparably with the first one. Contrary to the first case, the $\mathrm{B}^{+}$(curve 2) and $\mathrm{N}^{+}$(curve 3) implantation resulted in slight decreasing of PL intensity comparably with initial samples. The $\mathrm{N}^{+}$ doped sample has the spectrum with the same shape and

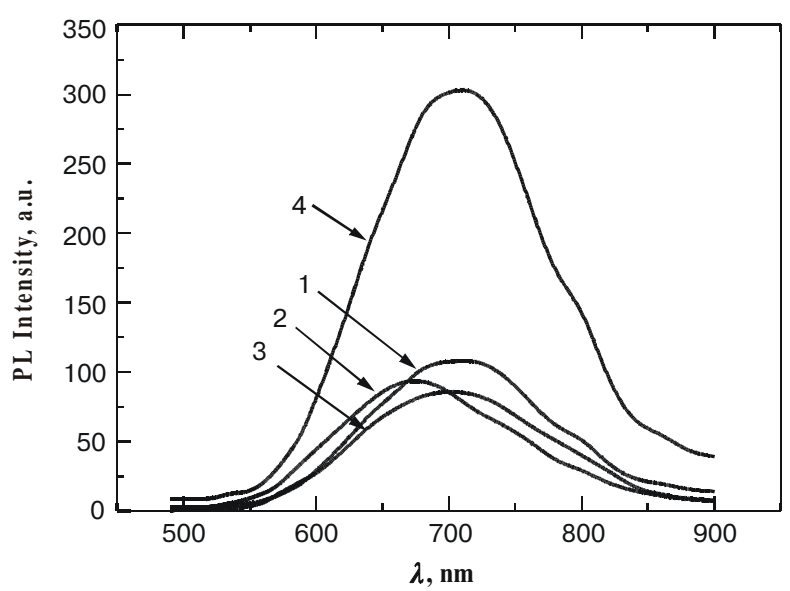

Fig. 2. Integrated PL spectra of the second porous silicon series formed on (1) initial (unimplanted) $\mathrm{Si}$ wafers and on the $\mathrm{Si}$ implanted with (2) $\mathrm{B}^{+}$ions, (3) $\mathrm{N}^{+}$ions, (4) $\mathrm{B}^{+}+\mathrm{N}^{+}$combined implantation. 


\section{A.G. Rozhin et al.: Activation of porous Si blue emission due to preanodization ...}

PL band position as initial one. As indicated above, this fact evidences in favor of the defect model correctness. On the other hand, the $\mathrm{B}^{+}$implanted samples both for two series have the PL band with maximum near $680 \mathrm{~nm}$. It was demonstrated [12-14] that the quantum confinement effect is manifested in the optical characteristics of nanoparticles by a shortwave shift of their optical spectrum due to introduction of charged particles. There are different explanations of this effect. The shift can be attributed to (i) an increase in the exciton energy under the action of an internal electric field of excess charges [12], (ii) a decrease in the oscillator strength for the exciton transition under the action of trapped electrons and holes [13], or (iii) the excess electrons occupying lower vacant levels of the nanoparticle, whereby a greater energy is required for exciting the electron to a higher valence level [14]. The curve 4 indicated influence of combined implantation of $\mathrm{B}^{+}+\mathrm{N}^{+}$ions onto PL properties second series samples. The compensation effect is more pronounced for the second series than for the first one.

Fig. 3 shows the nanosecond (ns) spectra of the studied second samples series. The ns spectrum for initial samples is characterized by two spectral bands. The photoluminescence from short-wave spectral range is usually $(450 \mathrm{~nm})$ connected with emission from Si nanocrystallites [11]. But it should be noted, that this emission appears only in the ns PL component of non treated sample, and it is not observed in integrated spectrum (see Figs 1 or 2) . However, the longwave emission is present in spectra, which attributed to appearance of quantum confinement effects. The ns spectra for implanted samples (curves 2,3,4 in Fig. 3) show only shortwave PL. The quenching of longwave ns PL is probably caused by the defects created during ion implantation.

In the following stage of investigation, we performed rapid thermal annealing (RTA) by heating the samples

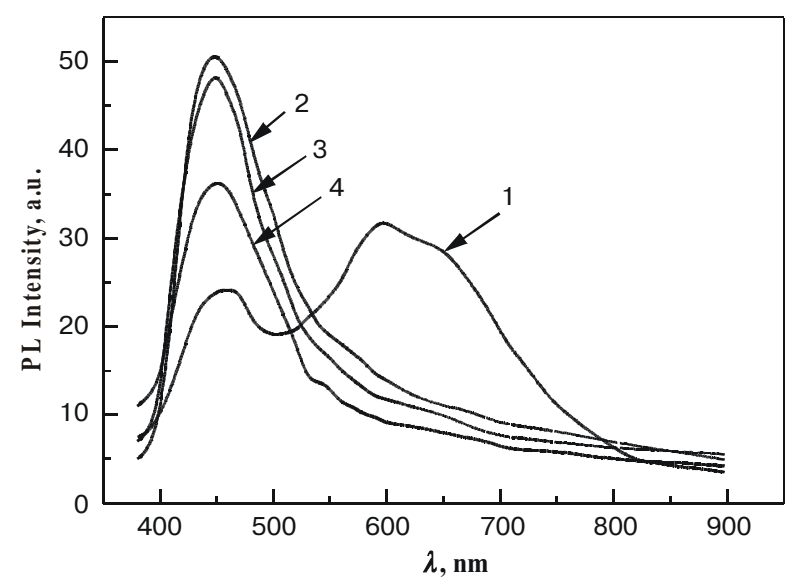

Fig. 3. PL spectra of the second porous silicon series measured with nanosecond time delay formed on (1) initial (unimplanted) Si wafers and on the Si implanted with (2) $\mathrm{B}^{+}$ions, (3) $\mathrm{N}^{+}$ions, (4) $\mathrm{B}^{+}+\mathrm{N}^{+}$combined implantation. for $30 \mathrm{~s}$ to $800 \mathrm{~K}$ (for first series) and $1100 \mathrm{~K}$ (for second series) in an argon atmosphere. As is seen from Fig. 4, this treatment results in the low-energy shift of the longwavelength emission line in the spectra of both the unimplanted sample and there doped by $\mathrm{B}^{+}+\mathrm{N}^{+}$. The shift can be explained by the annealing-induced enlarging of nanostructures. As it is known [15], porous Si possesses a laminar structure manifested in a distribution of the silicon wires diameter from small (near the surface) to large (in the depth). During the thermal annealing, the thin surface wires lose the radiative ability, and the emission occurs from the deeper layers containing thick wires. The drop in the PL intensity in the long-wavelength range is typical for annealing in the used temperature range [16].

In addition to the usual long-wavelength emission at 650-700 $\mathrm{nm}$, the RTA results in activation of the PL band at $450 \mathrm{~nm}$. The samples implanted with $\mathrm{B}^{+}$ions exhibit a very sharp increase in the PL intensity at $450 \mathrm{~nm}$ (Fig. 4, curve 2). Apparently, the RTA process electrically activated boron atoms in the subsurface layer of porous Si. The segregation of boron atoms at the silicon wires $\mathrm{SiO}_{\mathrm{x}}$ interface may lead to the appearance of additional energy levels in the bandgap, which would result in the high-energy PL. At the same time, this sensitization effect is not so pronounced in the samples implanted with a $\mathrm{B}^{+}+\mathrm{N}^{+}$combination (Fig. 2, curve 4), which is probably explained by a greater total implantation dose leading to a greater amount of implantation defects.

Fig. 5 show the integrated PL spectra for the samples of the second series, which has been annealed at $1100 \mathrm{~K}$ in Ar environment. The significant downshift of PL peak position was observed for all second series samples when compare with the non-annealed ones. This fact can be explained by structural difference of the second series samples. As we mentioned above, the second series samples has higher porosity, and their thermal annealing

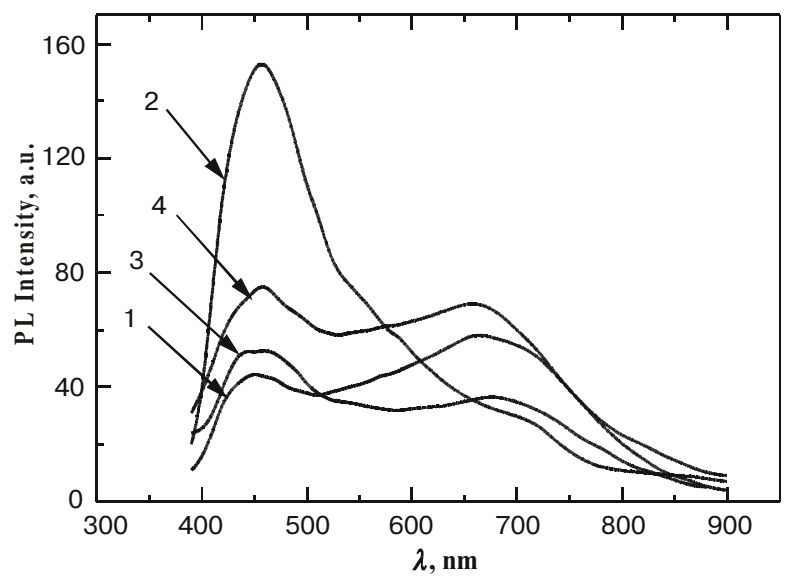

Fig. 4. The effect of RTA annealing (30 s at $800 \mathrm{~K})$ on the integrated PL spectra of the first porous silicon series formed on (1) initial (unimplanted) $\mathrm{Si}$ wafers and on the Si implanted with (2) $\mathrm{B}^{+}$ ions, (3) $\mathrm{N}^{+}$ions, (4) $\mathrm{B}^{+}+\mathrm{N}^{+}$combined implantation. For convenience the intensity of spectra $(1,3,4)$ are multiplied by the factor of 10 and (2) of 2. 


\section{A.G. Rozhin et al.: Activation of porous Si blue emission due to preanodization ...}

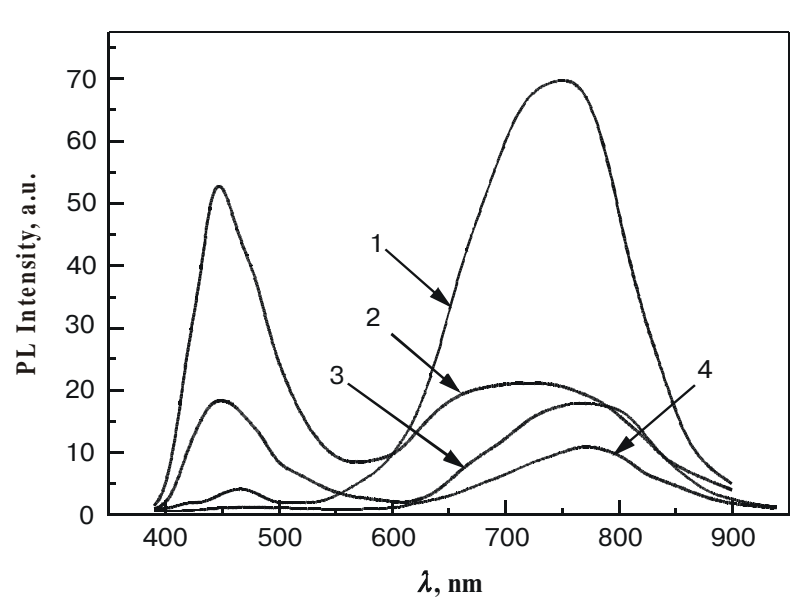

Fig. 5. The effect of RTA annealing ( $30 \mathrm{~s}$ at $1100 \mathrm{~K})$ on the integrated PL spectra of the second porous silicon series formed on (1) initial (unimplanted) $\mathrm{Si}$ wafers and on the Si implanted with (2) $\mathrm{B}^{+}$ions, (3) $\mathrm{N}^{+}$ions, (4) $\mathrm{B}^{+}+\mathrm{N}^{+}$combined implantation.

leads to emission from deeper layers. However, the PL in high energy spectral range has been observed only for samples formed on $\mathrm{B}^{+}$and $\mathrm{B}^{+}+\mathrm{N}^{+}$implanted wafers, that testifies the important role of boron for activation of porous Si high-energy emission. The boron atoms create the faster luminescent channel. In our opinion, the preferable is the emission mechanism from the intermediate impurities states created by the boron in the dielectric $\mathrm{SiO}_{\mathrm{x}}$ matrix. This assumption has been confirmed by the measurement of the PL spectra with nanosecond time delay (Fig. 6). In this case, the emission from the $\mathrm{B}^{+}$modified samples (Fig. 6, curve 2) is up to 50 times more intensive then that for other samples.

\section{Conclusion}

The influence of ion modification of initial Si wafers on porous Si PL properties has been studied. It was shown that $\mathrm{B}^{+}$or $\mathrm{N}^{+}$only implantation leads to reducing $\mathrm{PL}$ intensity. On the other hand, the combined $\mathrm{B}^{+}+\mathrm{N}^{+}$implantation causes the increasing PL intensity that explained by recombination active donor acceptor complex creation.

The RTA results in activation of the high-energy emission for the samples formed on the wafers modified by $\mathrm{B}^{+}$ implantation. As a result of boron segregation on the nano $\mathrm{Si}_{-} \mathrm{SiO}_{x}$ interface the additional impurity energy levels in $\mathrm{SiO}_{x}$ layer can be created being responsible for appearance of high energy PL band.

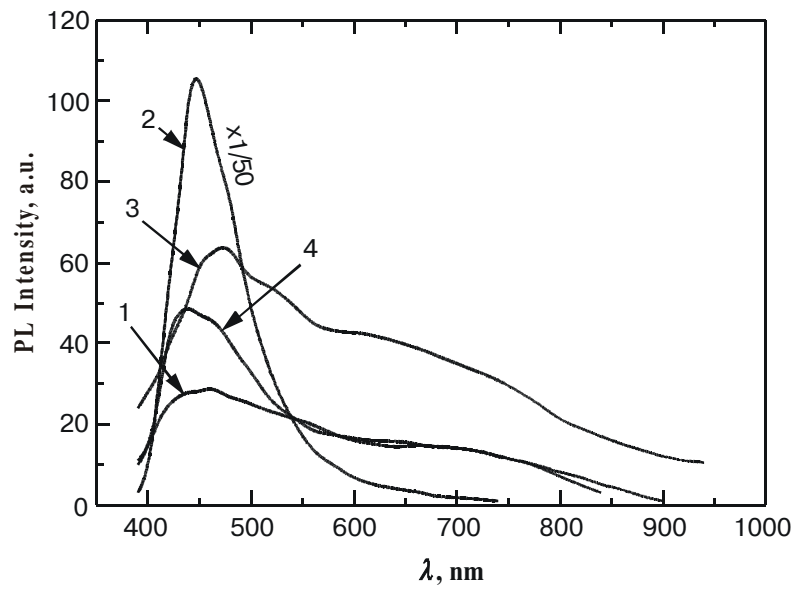

Fig. 6. The effect of RTA annealing ( $30 \mathrm{~s}$ at $1100 \mathrm{~K})$ on the PL spectra measured with nanosecond time delay of the second porous silicon series formed on (1) initial (unimplanted) Si wafers and on the Si implanted with (2) $\mathrm{B}^{+}$ions, (3) $\mathrm{N}^{+}$ions, (4) $\mathrm{B}^{+}+\mathrm{N}^{+}$ combined implantation. For convenience the intensity of the spectrum (2) is to 50 - fold reduced.

\section{References}

1. B Hamilton // Semicond. Sci. Technol. 10, pp. 1187-1207 (1995).

2. C. Peng, P.M. Fauchet, J.M. Rehm et al. // Appl. Phys. Lett. 64(10), pp. 1259-1261 (1994).

3. V.V. Ushakov, V.A. Dravin, N.N. Melnik et al. // Semiconductors 31(9), pp. 1126-1129 (1997).

4. A.A. Lebedev, A.M. Ivanov, A.D. Remenyuk et al. // Fizika $i$ Tekhnika Poluprovodnikov (in Russian) 30(1), pp.188-190 (1996).

5. X.L. Wu, F. Yan, X.M. Bao et al. // Appl. Phys. Lett. 68(15), pp. 2091-20936 (1996).

6. L.S. Liao, X.M. Bao, Z. F. Yang et al. // Appl. Phys. Lett. 66(18), pp.2382-2384 (1995).

7. L. Pavesi, G. Giebel, F.Ziglio et al. // Appl. Phys. Lett. 65(17), pp. 2182-2184 (1994).

8. L.T. Canham // Appl. Phys. Lett. 57(10), pp. 1046-1048 (1990).

9. Arun Madan, Melvin P. Shaw, The Physics and Applications of Amorphous Semiconductors // Academic Press INC, Harcourt Brace Jovanovich, Publisher Boston, 1989.

10. S.V. Svechnikov, A.V. Sachenko, G.A. Sukach et al.// Optoelectronika i poluprovodnikovaya tekhnika (in Ukrainian) 27, pp.3-29 (1994).

11. P.M. Fauchet, J.von Behren, K.D. Hirschman et al. // Phys. Stat. Sol. 165, pp.3-13 (1998).

12. A.Henglein, A.A.Kumat, E.Janata et al. // Chem. Phys. Lett. 132, pp. 133-135 (1986).

13. E. Helinski, P.Lucas, Y.Wang // J. Chem. Phys. 89, pp. 34353441 (1988).

14. B.E. Burstein // Phys. Rev. 93, pp. 632-633 (1954).

15. M.E. Kompan, I.Yu.Shabanov, V.I.Beklemyshin et al. // Fizika i Tekhnika Poluprovodnikov (in Russian) 30(6), pp.1095-1103 (1996).

16. Y. Kanemitsu // Phys. Rev. B 49(20), pp. 14732-14735 (1994). 